\title{
Three-year-olds are sensitive to semantic prominence during online language comprehension : A visual world study of pronoun resolution
}

\section{Pyykkönen, Pirita}

\section{0-01-01}

Pyykkönen, P, Matthews, D \& Järvikivi , J 2010 , ' Three-year-olds are sensitive to semantic prominence during online language comprehension : A visual world study of pronoun resolution ' , Language and Cognitive Processes , vol. 25 , no. 1 , pp. 115-129 . https://doi.org/10.1080/016s

http://hdl.handle.net/10138/24704

https://doi.org/10.1080/01690960902944014

submittedVersion

Downloaded from Helda, University of Helsinki institutional repository.

This is an electronic reprint of the original article.

This reprint may differ from the original in pagination and typographic detail.

Please cite the original version. 
This article was downloaded by: [Library of Behavioural Sciences]

On: 26 August 2010

Access details: Access Details: [subscription number 917681240]

Publisher Psychology Press

Informa Ltd Registered in England and Wales Registered Number: 1072954 Registered office: Mortimer House, 3741 Mortimer Street, London W1T 3JH, UK

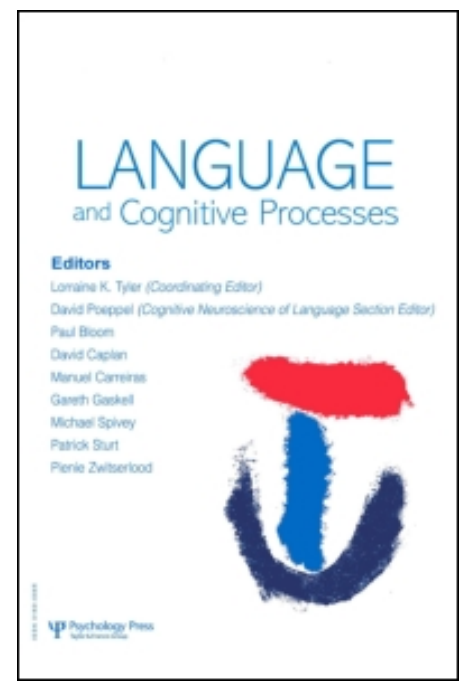

\section{Language and Cognitive Processes}

Publication details, including instructions for authors and subscription information:

http://www.informaworld.com/smpp/title content=t713683153

\section{Three-year-olds are sensitive to semantic prominence during online} language comprehension: A visual world study of pronoun resolution Pirita Pyykkönen ${ }^{\text {ab }}$; Danielle Matthews ${ }^{c}$; Juhani Järvikivi ${ }^{\mathrm{d}}$

${ }^{\mathrm{a}}$ Department of Psychology, University of Turku, Finland ${ }^{\mathrm{b}}$ Department of Computational Linguistics, Saarland University, Germany ${ }^{\mathrm{c}}$ Max Planck Child Study Centre, School of Psychological Sciences, University of Manchester, UK ${ }^{\mathrm{d}}$ Max Planck Institute for Psycholinguistics, Nijmegen, The Netherlands

First published on: 22 July 2009

To cite this Article Pyykkönen, Pirita, Matthews, Danielle and Järvikivi, Juhani(2010) 'Three-year-olds are sensitive to semantic prominence during online language comprehension: A visual world study of pronoun resolution', Language and Cognitive Processes, 25: 1, 115 - 129, First published on: 22 July 2009 (iFirst)

To link to this Article: DOI: $10.1080 / 01690960902944014$

URL: http://dx.doi.org/10.1080/01690960902944014

\section{PLEASE SCROLL DOWN FOR ARTICLE}

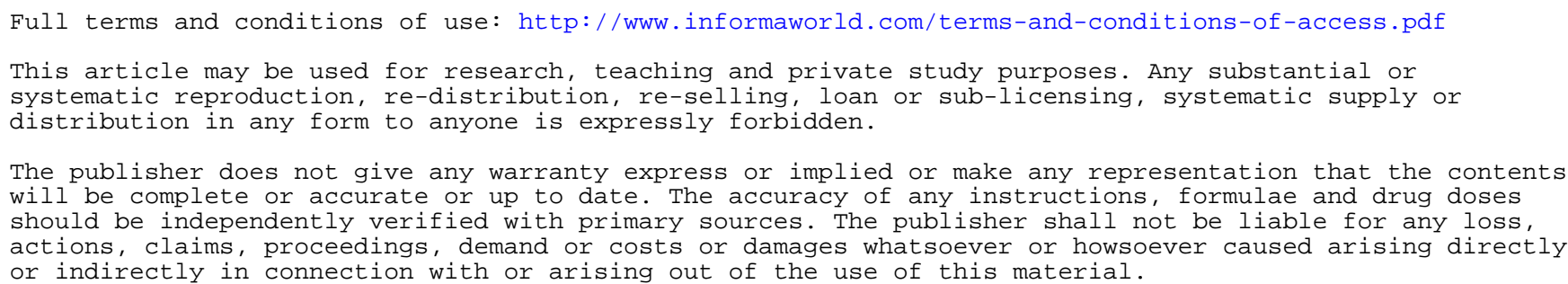




\title{
Three-year-olds are sensitive to semantic prominence during online language comprehension: A visual world study of pronoun resolution
}

\author{
Pirita Pyykkönen \\ Department of Psychology, University of Turku, Finland, and Department of \\ Computational Linguistics, Saarland University, Germany \\ Danielle Matthews \\ Max Planck Child Study Centre, School of Psychological Sciences, \\ University of Manchester, UK \\ Juhani Järvikivi \\ Max Planck Institute for Psycholinguistics, Nijmegen, The Netherlands
}

\begin{abstract}
Recent evidence from adult pronoun comprehension suggests that semantic factors such as verb transitivity affect referent salience and thereby anaphora resolution. We tested whether the same semantic factors influence pronoun comprehension in young children. In a visual world study, 3-yearolds heard stories that began with a sentence containing either a high or a low transitivity verb. Looking behaviour to pictures depicting the subject and object of this sentence was recorded as children listened to a subsequent sentence containing a pronoun. Children showed a stronger preference to look to the subject as opposed to the object antecedent in the low transitivity condition. In addition there were general preferences (1) to look to the subject
\end{abstract}

\footnotetext{
Correspondence should be addressed to Pirita Pyykkönen, FR 4.7 Psycholinguistics, Department of Computational Linguistics, Saarland University, Building C7.1, 66041 Saarbrücken, Germany. E-mail: pirita@CoLi.Uni-SB.DE

This research was supported by grants from The Academy of Finland (no 213731), the Finnish Cultural Foundation, Jenny and Antti Wihuri Foundation and the Graduate School of Psychology in Finland awarded to the first author, a Max Planck Postdoctoral Fellowship awarded to the second author and grant no. 106418 from The Academy of Finland awarded to the third author. Thanks to Ben Tatler for help with recordings, Silke Harboldt for data coding, Matt Crocker and anonymous reviewers for helpful feedback, and the parents and children who participated.
}

(C) 2009 Psychology Press, an imprint of the Taylor \& Francis Group, an Informa business http://www.psypress.com/lcp

DOI: $10.1080 / 01690960902944014$ 
in both conditions and (2) to look more at both potential antecedents in the high transitivity condition. This suggests that children, like adults, are affected by semantic factors, specifically semantic prominence, when interpreting anaphoric pronouns.

Keywords: Language acquisition; Pronoun resolution; Semantic prominence; Transitivity; Visual world paradigm.

\section{INTRODUCTION}

Studies of adult pronoun comprehension have shown that, in the absence of definite disambiguating information such as gender (Arnold, Eisenband, Brown-Schmidt, \& Trueswell, 2000), adults tend to assume that pronouns refer back to the most prominent entity in the previous discourse (Almor, 1999; Ariel, 1988; Givon, 1983; Gundel, Hedberg, \& Zacharski, 1993). The factors influencing prominence can be roughly divided into structural and semantic: Structural (or syntactic) prominence is derived from the surface structure of the sentence (McKoon, Greene, \& Ratcliff, 1993), and the antecedent is made structurally prominent by presenting it for example as the local discourse topic, the subject and/or the first mentioned referent in the preceding phrase/ sentence (Foraker \& McElree, 2007; Gernsbacher \& Hargreaves, 1988; Gordon, Grosz, \& Gilliom, 1993; Järvikivi, Van Gompel, Hyönä, \& Bertram, 2005). In contrast, semantic prominence refers to the impact or role of the entities in the sentence which cannot be derived from the surface structure itself, such as semantic roles (Fillmore, 1968; Jackendoff, 1972; Speas, 1990). While structural prominence has a strong effect on referent accessibility, it could be argued that most studies in anaphor resolution rarely distinguish between structural and semantic prominence: syntactic subjects are almost always also prototypically semantic agents and objects patients (but see Stevenson, Crawley, \& Kleinman, 1994). The question thus arises as to the degree to which semantic prominence influences reference resolution.

Recent evidence suggests that the semantics of a verb and its associated arguments has consequences for referential processing in adults. Dowty (1991) defined a number of verb properties, which make their arguments (subject and object) prototypically more or less agent- or patient-like. Together these properties affect the degree of the transitivity of the verb: The more prototypically agent- and patient-like features its subject and object exhibit, the more highly transitive the verb is. ${ }^{1}$ For example, in the sentence The panda hit the parrot, the verb hit can be said to be highly transitive. As is illustrated in Table 1, the subject of hit has many prototypical (or

\footnotetext{
${ }^{1}$ It is important to note that although intransitive verbs are at one end of the transitivity scale (Hopper \& Thompson, 1980), in the current paper we are interested in high and low transitive verbs that are grammatically all transitive such as hit/see.
} 
TABLE 1

The proto-agent and proto-patient properties of the subject and object arguments of the verbs Hit and See

\begin{tabular}{clcc}
\hline & & Hit & See \\
\hline $\begin{array}{c}\text { Proto-Agent } \\
\text { properties } \\
\text { of the subject }\end{array}$ & Volitional involvement & $\checkmark$ & $\checkmark$ \\
& Sentience/perception & $\checkmark$ & $\checkmark$ \\
$\begin{array}{c}\text { Causing event/change of state } \\
\text { Moto-Patient }\end{array}$ & Movement & $\checkmark$ & \\
properties & Undergo change of state & $\checkmark$ & \\
& Incremental theme & & \\
& $\begin{array}{l}\text { Causally affected } \\
\text { Stationary }\end{array}$ & $\checkmark$ \\
\hline
\end{tabular}

proto-)agent properties and the object has many proto-patient properties. If we switched the verb from hit to saw, the properties of the subject and object would be less prototypically those of an agent or a patient. Indeed, in the case of this lower transitivity verb, the object displays no prototypical properties of a patient at all.

Verb transitivity has not been directly manipulated in studies of adult online language comprehension. However, in a series of self-paced reading experiments, Rose (2005) looked at the argument role properties of the verbs and showed that they affect adult online processing. For example, after both $1 \mathrm{a}$ and $1 \mathrm{~b}$,

(1a) John sprayed some paint on a wall

(1b) John sprayed a wall with some paint

participants were faster to read pronoun and definite noun phrase continuations like It dribbled down and made a mess referring to the semantic theme that is always assumed to be higher in the transitivity hierarchy than continuations referring to the semantic goal like $I t$ was big and needed two coats (see also Speas, 1990). Moreover, this was the case irrespective of the syntactic position of the antecedents, i.e., whether the theme preceded the goal or vice versa. In contrast, in the judgement task in which participants were asked to rate the above continuations, they found the former more suitable after (1a) than (1b), suggesting that both syntactic and semantic prominence are used to assign the referent for an ambiguous pronoun. Even though this study was not designed to manipulate verbs that carry different proto-role properties, but instead manipulate the relative order of the referents (theme and goal) of the following pronoun, it shows that semantic prominence may play a significant role in pronoun resolution. 
The aim of the current study was to investigate whether children are sensitive to semantic prominence in spoken language comprehension. Taking a more direct approach than Rose (2005), semantic prominence was manipulated by using two groups of verbs that varied in their relative transitivity. An additional aim was to see whether transitivity interacts with potential effects of structural prominence. There is some controversy in the literature as to how sensitive children are to structural prominence when interpreting pronouns. Song and Fisher $(2006,2007)$ conducted a series of studies in which they found that 2-and 3-year-olds were adult-like in that they treated pronouns as co-referential with the subject (and first mentioned referent) in the prior linguistic context. This effect of subjecthood/first mention appeared, at the earliest, between 1 and 2 seconds after pronoun onset in an experiment where both possible antecedents had been mentioned twice in the same order before the pronoun was heard (2006, Experiment 4). In contrast, Arnold et al. (Arnold, Brown-Schmidt, \& Trueswell, 2007; Arnold, Brown-Schmidt, Trueswell, \& Fagano, 2005) found no reliable evidence that 5-year-olds preferred first-mentioned characters as referents for ambiguous pronouns, although in this experiment (Arnold et al., 2007, Experiment 2) children had less than a second to show such an effect before disambiguating information became available. It would thus appear that children might only be sensitive to order of mention when it is a wellestablished cue (i.e., encountered in at least two sentences before the one containing the pronoun), and that they are slower to use this information than (1) they are to use gender information and (2) adults are to use order of mention information. With the current study we add to this growing literature by investigating the time course of 3-year-olds' pronoun comprehension as mediated not only by subjecthood/order of mention (established with only one sentence in this study) but also semantic prominence measured in terms of verb transitivity.

\section{Verb transitivity}

Perhaps one of the most basic semantic dimensions verbs have is that of transitivity (Hopper \& Thompson, 1980). The degree of transitivity of a given verb can be defined by how many prototypically agent-like or patientlike features, or proto-role properties, its arguments, subject and object, exhibit, as shown in Table 1 (Dowty, 1991; Kako, 2006). Hopper and Thompson (1980) showed that the lower the degree of transitivity of the verb is, the more backgrounded its arguments are in discourse; and, vice versa, the higher the transitivity of the verb, the more foregrounded, and therefore more accessible, its arguments are.

Based on the above literature it is expected that when people hear a pronoun 'he' after a high transitivity sentence, it is likely that both subject and object 
(the panda and the parrot in the previous example) are highly accessible as antecedents for the pronoun as they exhibit several prototypically agent- and patient-like features, and therefore they compete to become the antecendent for the pronoun following a high transitive verb. In contrast, following the low transitivity sentence, neither the subject nor object are semantically highly prominent, and are thus less accessible as antecedents as they do not exhibit many prototypically agent- or patient-like features. Moreover, as we saw that the parrot did not exhibit any of the prototypically object-like properties following the low-transitive verb, it can be hypothesised that the panda, that does exhibit some of the proto-agent properties, will be more foregrounded in the discourse following the low transitive verb and therefore more accessible as an antecedent for the pronoun than the parrot. $^{2}$

In the current study we adopted the visual world method (Tanenhaus, Spivey-Knowlton, Eberhard, \& Sedivy, 1995), and presented children with four-sentence stories auditorily while they were looking at pictures on a wide computer screen (see Figure 1). The stories began with a sentence that contained either a high or low transitivity verb. The second sentence always had a question "Do you know what happened next?" before a pronoun was heard at the beginning of the third sentence. By videoing the children's eye movements after the pronoun in the third sentence, we were able to assess the extent to which children had interpreted one of the characters as being the referent of the pronoun. In order to get as clear an idea as possible as to how the pronoun was understood, we targeted only the trials where the children were not looking at the subject or object character at the pronoun onset. If children are sensitive to verb transitivity, then they should be expected to consider both subject and object as a suitable antecedent for the pronoun in high transitive condition, i.e., they might look to the characters more in the high transitivity condition than in the low transitivity condition. They might also show a general preference for the subject and first-mentioned character of the first transitive sentence. Finally, if the relative number of proto-role properties has consequences for semantic prominence, as argued above, it is possible that the syntactic role of the antecedent would interact with verb transitivity such that children would look relatively more to the object after hearing a high transitivity verb than after hearing a low transitivity verb.

\footnotetext{
${ }^{2}$ In adult language processing Rose (2005) observed that an effect of verb transitivity may be more pronounced for object than subject antecedents. In this case, the object argument of a low transitivity verb, such as see, might be considered less likely for subsequent mention than referents previously realised as subjects or as arguments to high transitivity verbs. Intuitively too, we are more likely to expect the parrot to do something after having been hit than after having been seen. We are thus more likely to expect that something will be said about the parrot after hearing a high transitivity sentence. In such a way, semantic prominence should impact on the accessibility of the arguments in the unfolding discourse and the interpretation of subsequent pronouns.
} 

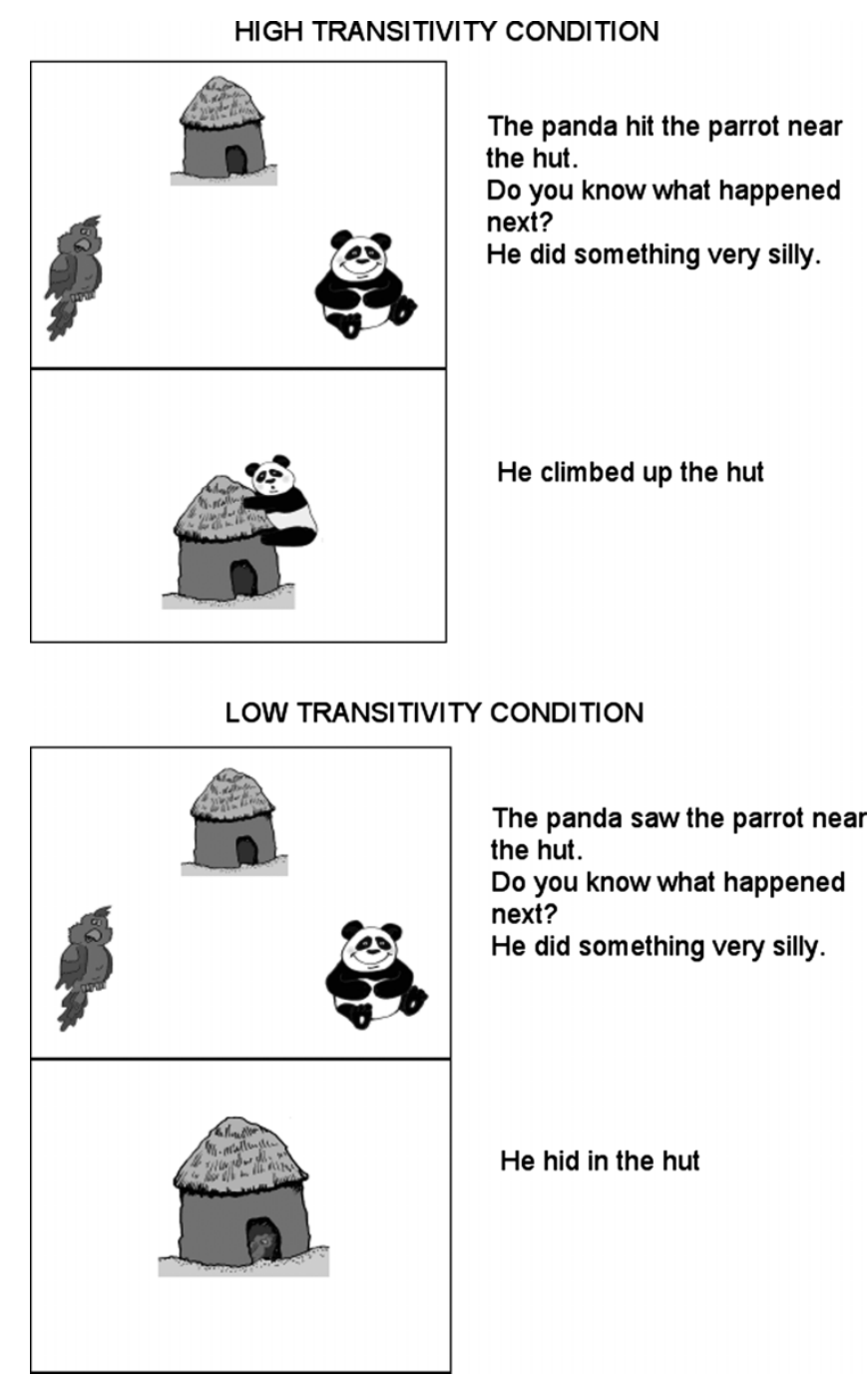

Figure 1. Example stimuli for high and low transitivity conditions.

\section{METHOD}

\section{Participants}

Nineteen normally developing, mono-lingual, English-speaking 3-year-olds participated in the experiment (11 girls; mean age $3 ; 5$, range $3 ; 2-3 ; 7)$. Four children were excluded because they did not complete the test or over $50 \%$ of 
their data were not codable. Children were tested in a child-friendly university laboratory. Parental consent was obtained prior to participation.

\section{Materials}

We selected 30 reversible transitive verbs that occurred frequently in childdirected speech in the Manchester Corpus made available on the CHILDES database (MacWhinney, 2000; Theakston, Lieven, Pine, \& Rowland, 2001). Sixty undergraduates from the University of Manchester rated the verbs for their transitivity by completing a questionnaire based on that of Kako (2006, Experiment 1). Participants read each verb in a simple transitive sentence (e.g., Jane chased Kate) and rated, on a seven-point Likert scale, the agent- and patient-like properties of the subject and object (see Appendix). We selected the 10 verbs rated as having the most agent- and patient-like properties as our high transitivity verbs. The 10 verbs rated lowest were selected as our low transitivity verbs. The remaining verbs were used for filler sentences. All 30 verbs are presented in Table 2. The verbs in the two experimental conditions did not differ significantly in terms of $\log$ frequency in the Manchester Corpus $(t<1)$ but did differ in terms of mean transitivity ratings: high transitive, 5.25; low transitive, $4.21 ; t(18)=7.157, p<.0001$.

Twenty mini-stories containing ten high and ten low transitivity verbs were created. The first sentence of each story introduced two characters and a location. The third sentence began with the critical pronoun he (see Figure 1). The stories were read by a male British English speaker with normal declarative and question sentence intonations and recorded onto a computer disk with a sampling frequency of 22,050 Hz using Praat phonetic software (Boersma, 2001). One story was selected as the base experimental story and was used in all items to reduce prosodic variability between

TABLE 2

Stimulus verbs (mean transitivity ratings given in parentheses)

\begin{tabular}{lll}
\hline High transitivity verbs & Low transitivity verbs & Filler verbs \\
\hline Fed (5.49) & Bumped (4.73) & Frightened (5.14.) \\
Pinched (5.29) & Teased (4.72) & Scared (5.14) \\
Phoned (5.28) & Found (4.55) & Pulled (5.11) \\
Cuddled (5.24) & Loved (4.43) & Tickled (5.10) \\
Squashed (5.24) & Hated (4.37) & Pushed (5.09) \\
Kissed (5.23) & Ignored (4.32) & Poked (5.06) \\
Squeezed (5.21) & Liked (4.10) & Caught (4.95) \\
Kicked (5.18) & Heard (3.69) & Chased (4.94) \\
Banged (5.16) & Lost (3.62) & Left (4.87) \\
Hit (5.15) & Saw (3.53) & Upset (4.74) \\
\hline
\end{tabular}


conditions and items. Thus, the two middle sentences were identical in each test story. The first sentence was identical in the two conditions except for the order of the nouns phrases (counterbalanced) - i.e. the same verb was spliced in to each story. Ten filler stories with nouns instead of pronouns were created using a similar procedure.

The children were presented with a picture on a $50 \times 30 \mathrm{~cm}$ computer screen as they listened to the first three sentences. The location mentioned in the first sentence always appeared in the centre top/bottom of the screen. The two animal referents appeared to the far left and right of the screen (with a minimum of $15 \mathrm{~cm}$ between them). Fifteen pairs of different animal pictures (e.g., parrot and panda) were used twice each (for a total of 30 stories). To reduce effects of individual animal preferences, each pair of animals was used once with a high and once with a low transitivity verb. An additional counterbalancing condition was added so that each animal acted as both subject and object. For a given pair, each animal was seen once on the right of the screen and once on the left. Following the third, critical sentence, a sentence along with a disambiguating picture with one of the animals was presented. Each animal appeared in a disambiguating picture once per list. Disambiguating pictures were counterbalanced such that half of the pictures disambiguated to the subject and the rest to the object. All animals were drawn to be the same size with eyes looking straight ahead (never toward the other character).

\section{Design and procedure}

After a period of free play, the children were sat $40 \mathrm{~cm}$ from the computer screen with their parent sat behind them and the experimenter to the left or the right (counterbalanced). The children were first presented with pictures of each animal in turn and asked to name them (in rare cases of misnaming, children were reminded of the animal name). When they had seen all the animals, they were told that 'some of them might do something silly now. Let's see who does something silly.'

Each child was presented with all 30 stories from one of four lists counterbalanced for the grammatical role of the two animal characters in the first sentence and order of presentation of stories ( 2 orders). The lists were created in pseudo-random order so that they began with a filler item and were followed by two test items, one from each condition and continued in randomly ordered triplets of filler and test items.

Before each story was played, a star appeared on the screen. When the child was looking at the star, the experimenter started the next story. The first picture appeared for 1 second before the sound file started and remained for a second after it ended. The sentence containing the critical pronoun lasted $1291 \mathrm{~ms}$ and was followed by $2709 \mathrm{~ms}$ of silence (i.e., over $4000 \mathrm{~ms}$ between 
pronoun onset and disambiguation picture). The disambiguating picture then appeared, the last sentence played and then the star returned to the screen. Children's eye movements were videoed using a Panasonic NV-GS55 mini DV digital video camera mounted at the centre top of the computer screen. ${ }^{3}$ On occasion children would look up to the experimenter when they heard the question that came as the second sentence in the story. In such cases, the experimenter looked directly to the centre of the screen in order to redirect the child's attention there in time for the critical sentence without biasing towards either interpretation. The experiment lasted approximately 20 minutes.

\section{Data coding}

Children's eye movements for each 40-ms frame following pronoun onset were coded as looking to the left (animal 1), right (animal 2), or elsewhere (location or away) by a research assistant blind to the hypotheses of the experiment using INTERACT ${ }^{\odot}$ video coding software. The percentage of non-codable trials was $15.11 \%, 14.0 \%$, and $15.2 \%$ for the fillers, high transitive and low transitive conditions, respectively.

\section{RESULTS}

All trials where the child was already looking at the subject or object pictures at the pronoun onset were discarded before data analysis $(41.8 \%$ of codable trials). There was no effect of verb condition or grammatical role on the number of trials discarded at the pronoun onset (Grammatical role: $L R \chi^{2}=$ 1.97, $p>.15$; Verb transitivity and Grammatical role $\times$ Verb transitivity $\left.L R \chi^{2} \mathrm{~s}<1\right)$.

Figure 2 presents the number of looks to the subject and the object character in the high and low transitivity verb conditions for each 40-ms frame within the first $2800 \mathrm{~ms}$ after the onset of the pronoun he.

For statistical analyses the data from the $40-\mathrm{ms}$ frames were pooled into five time windows of $520 \mathrm{~ms}$. Because it takes about $200 \mathrm{~ms}$ to plan and launch an eye movement (Matin, Shao, \& Boff, 1993), we analysed the five consecutive time segments corresponding to 200-2800 milliseconds after pronoun onset (the duration of the pronoun was $130 \mathrm{~ms}$ ). There were no significant effects within the first $200 \mathrm{~ms}$ (Fisher's Exact test - especially suited for categorical data when the number of observations are small - twosided, $p=.229$ ). For each window, we conducted Hierarchical Log-linear analyses with Verb type (high/low) and Grammatical role (subject/object) as

\footnotetext{
${ }^{3}$ This camera does not guarantee time locking of audio and visual signals although time locking was checked at the point of coding and found to be satisfactory.
} 


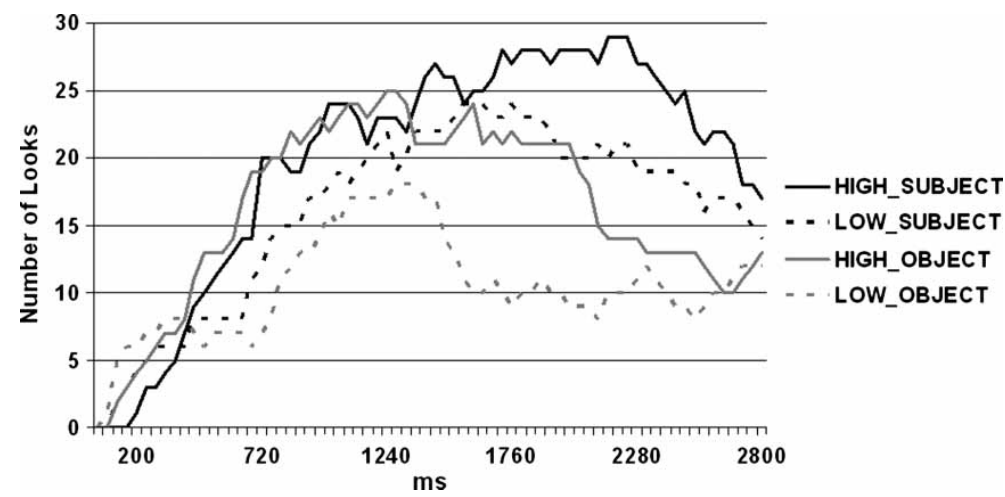

Figure 2. Number of total looks to subject and object pictures as a function of verb transitivity and time from $0-2800 \mathrm{~ms}$ after pronoun onset.

factors with the number of looks to the pictures representing the subject and the object antecedents as the dependent measure (for log-linear models, see Howell, 2002; for the application of log-linear models to visual world data, see Altmann \& Kamide, 2007, 2009; Huettig \& Altmann, 2005; Knoeferle \& Crocker, 2006, 2007; Knoeferle, Crocker, Scheepers, \& Pickering, 2005; Scheepers, 2003; Weber, Grice, \& Crocker, 2006). The results are summarised in Table 3.

An effect of verb type was observed such that children looked more to both characters when they heard a high transitivity verb than when they heard a low transitivity verb. This effect was significant in the time windows between 200 and $2800 \mathrm{~ms}$, but not in the 0-200 time window, indicating that the effect was due to the pronoun. This effect was qualified by an interaction with grammatical role in the three time windows between 720 and $2280 \mathrm{~ms}$. Log-linear contrasts showed that between $720-1760 \mathrm{~ms}$ the preference to look more at the subject was significant for the low transitivity verbs:

TABLE 3

Results of time course analyses $(d f=1)$

\begin{tabular}{lccc}
\hline & Verb type & Grammatical role & Interaction \\
\hline Time window & LR $\chi^{2}$ & $L R \chi^{2}$ & $L R \chi^{2}$ \\
$200-720$ & $15.49^{* * *}$ & $<1$ & 2.20 \\
$720-1240$ & $27.35^{* * *}$ & $<1$ & $4.32^{*}$ \\
$1240-1760$ & $22.97^{* * *}$ & $25.38^{* * *}$ & $11.19^{* * *}$ \\
$1760-2280$ & $39.54^{* * *}$ & $77.33^{* * *}$ & $5.70^{*}$ \\
$2280-2800$ & $9.22^{* *}$ & $60.97^{* * *}$ & $<1$ \\
\hline
\end{tabular}

Note: ${ }^{*} p<.05 ; * * p<.01 ; * * * p<.001$. There were no significant differences during the first $200 \mathrm{~ms}$ from the pronoun onset $(p>.22)$. 
720-1240: $\left.L R \chi^{2}(1)=5.59, p<.05 ; 1240-1760: L R \chi^{2}(1)=33.84, p<.001\right)$ but not for the high transitivity verbs: 720-1240: $L R \chi^{2} \mathrm{~s}<1 ; 1240-1760$ : $\left.L R \chi^{2}(1)=2.72, p=.10\right)$. In the next time window $(1760-2280 \mathrm{~ms})$ the subject preference was significant for both verb types, but more pronounced in the low transitivity condition: high transitivity: $L R \chi^{2}(1)=22.48, p<.001$; low transitivity: $L R \chi^{2}(1)=54.54, p<.001$. A main effect of grammatical role was also observed such that children looked more to the character referred to by the grammatical subject of the verb than the character referred to by the object. This effect was significant in the 1240-2800 ms windows. ${ }^{4}$

\section{DISCUSSION}

The current results clearly indicate that semantic prominence affects children's sentence comprehension. There was a strong effect of verb transitivity on three-year-olds' looking behaviour upon hearing the critical pronoun. Children looked more overall to both the subject and the object of

\footnotetext{
${ }^{4}$ In order to inspect the possible patterns in the discarded data set, we analysed the corresponding time windows beginning at the pronoun onset: (significant and marginally significant results will be reported): Within $0-200 \mathrm{~ms}$ there were significantly more looks to subject than object antecedents $\left(L R \chi^{2}=4.51, p<.05\right)$ and marginally more looks to low than high transitive antecedents $\left(L R \chi^{2}=3.37, p=.07\right)$. There were marginally more looks to object than subject antecedents within the next $200-720 \mathrm{~ms}$ window $\left(L R \chi^{2}=3.42, p=.07\right)$; The were marginally more looks to subject than object antecedents within $720-1240 \mathrm{~ms}\left(L R \chi^{2}=2.86, p=\right.$ .09); Within the next 1240-1760 time window we found significant main effects of grammatical role $\left(L R \chi^{2}=15.78, p<.001\right)$, verb type $\left(L R \chi^{2}=17.03, p<.001\right)$ and a significant interaction $\left(L R \chi^{2}=10.75, p<.01\right)$. Further inspection of the data revealed that the interaction was entirely due to the fact that there were significantly more looks to the high transitive subject than to any other antecedent (high subject vs. low subject/high object vs. low object: all $L R \chi^{2} \mathrm{~s}>26.00$, $p \mathrm{~s}<.001$ ) whereas there were no differences between any of the other 3 conditions (all $L R \chi^{2} \mathrm{~s}<$ 1); The last two windows of 1760-2280 and 2280-2800 showed only significant main effects denoting more looks to subject than object and high transitive than low transitive antecedents (all $L R \chi^{2} \mathrm{~s}>9.60, p \mathrm{~s}<.01$ ).

Despite the fact that the patterns in the two latest time windows (1760-2280 and 2280 $2800 \mathrm{~ms}$ ) accord with our main results, any interpretation of the patterns in the discarded data are seriously hampered by the fact that after the first $200 \mathrm{~ms}$ the overall number of the discarded looks drops quickly and reaches the asymptote in the next time segment: there were proportionately significantly more looks overall in the first $200 \mathrm{~ms}$ than the next $(200-720 \mathrm{~ms})$ time segment $\left(L R \chi^{2}=10.82, p=.001\right)$ but no difference between this and any of the subsequent time segments overall $(p s>.18)$. Apart from the amount of looks to high transitive subject, however, the looks to the subject and object antecedents in all other conditions decreased linearly after the first $200 \mathrm{~ms}$ (next time segment: $82.5 \%$; last time segment: $57.5 \%$ ). Moreover, even though the looks to high subject antecedents did not drop as drastically and steadily as for the other conditions, in none of the following segments did the looks reach the same level compared to their level at pronoun onset (highest: $91 \%$; lowest: $72 \%$ ).
} 
the high transitivity verbs but their preference for the subject was far stronger and emerged earlier in the low transitivity condition.

The current study demonstrates that semantic prominence contributes to referent salience in children as young as 3 years old. Higher transitivity verbs depicted events with participants that had more prominent semantic properties and thus these participants were more accessible as potential referents for ambiguous pronouns. This stimulated increased looking behaviour to the referents. Lower transitivity verbs stimulated less looking behaviour overall and in particular towards the object of the low transitivity verb, as would be predicted by the transitivity hierarchy (Hopper \& Thompson, 1980; Rose, 2005). The fact that the effect of verb semantics arose particularly quickly might suggest that also children may use the relative salience of the participants in the event to generate expectations about the upcoming discourse (Altmann \& Kamide, 1999; Koornneef \& Van Berkum, 2006). This would be in line with the Expectancy Account (Arnold, 2001; Arnold et al., 2007; Arnold \& Lao, 2007), which proposes that the relative salience of the participants in an event affects the likelihood that these participants will be mentioned in the upcoming discourse, thus affecting their accessibility as potential referents (see, however, Pyykkönen \& Järvikivi, in press).

One potential concern with the current study is that, because transitivity is defined in terms of the degree of agent- and patient-likeness, the imageability of the verbs covaries with how transitive they are. (Verbs like hit denote more concrete actions that were not directly depicted on the screen, while verbs like see denote more abstract actions that could be more easily depicted by the presented scenes.) Therefore we cannot rule out the possibility that imageability contributed to the observed effects. Therefore, if the children were more confused in the high transitive condition, we should have arguably observed more looks away from the characters in this condition, which was not the case, or alternatively there would have been more fixations back and forth between the potential characters. However, we did not find that the pronoun in the low transitive condition was resolved more often than in the high transitive condition. Effects of imageability would also not predict either the subject preference or the interaction that we observed.

In addition to semantic effects, we also find an effect of structural prominence in child pronoun resolution. The observed preference to look to the subject (and first-mentioned) character of the first sentence replicates Song and Fisher's $(2006,2007)$ findings in even more stringent test conditions. Whereas in their study both possible antecedents were mentioned at least twice before the pronoun, making the first-mentioned antecedent highly prominent, we mentioned each character only once and the subject preference appeared slightly later but was robust nonetheless. The fact that this preference was fairly late to appear and was affected by verb type 
might explain why it has not been consistently observed in previous studies (Arnold et al., 2005, 2007). Our study also differed from previous experiments in using transitive stimuli rather than reciprocal predicates (e.g., Puppy is having lunch with Froggy). We therefore cannot rule out the possibility that an effect of the semantic prominence of the agent-subject in our study contributed to the effect of subjecthood/first mention. In addition, as the temporal adverbial 'next' in the second sentence explicitly invited the children to anticipate the upcoming event this may have strengthened the subject preference somewhat, as is observed with adults (Stevenson, Knott, Oberlander, \& McDonald, 2000).

To conclude, this study demonstrates semantic effects on young children's online comprehension of pronouns. This supports the idea that verb transitivity is an important factor affecting semantic prominence, which in turn influences antecedent accessibility and the subsequent resolution of ambiguous pronouns.

Manuscript received January 2008

Revised manuscript received March 2009

First published online July 2009

\section{REFERENCES}

Almor, A. (1999). Noun-phrase anaphors and focus: The informational load hypothesis. Psychological Review, 106, 748-765.

Altmann, G. T. M., \& Kamide, Y. (1999). Incremental interpretation of verbs: Restricting the domain of subsequent reference. Cognition, 73, 247-264.

Altmann, G. T. M., \& Kamide, Y. (2007). The real-time mediation of visual attention by language and world knowledge: Linking anticipatory (and other) eye movements to linguistic processing. Journal of Memory and Language, 57, 502-518.

Altmann, G. T. M., \& Kamide, Y. (2009). Discourse-mediation of the mapping between language and the visual world: Eye movements and mental representation. Cognition, 111, 55-71.

Ariel, M. (1988). Referring and accessibility. Journal of Linguistics, 24, 65-87.

Arnold, J. E. (2001). The effects of thematic roles on pronoun use and frequency of reference. Discourse Processes, 31, 137-162.

Arnold, J. E., Brown-Schmidt, S., \& Trueswell, J. (2007). Children's use of gender and order-ofmention during pronoun comprehension. Language and Cognitive Processes, 22, 527-565.

Arnold, J. E., Brown-Schmidt, S., Trueswell, J. C., \& Fagano, M. (2005). Children's use of gender and order of mention during pronoun comprehension. In J. Trueswell \& M. Tanenhaus (Eds.), Approaches to studying world-situated language use (pp. 261-281). Cambridge, MA: MIT Press.

Arnold, J. E., Eisenband, J. G., Brown-Schmidt, S., \& Trueswell, J. C. (2000). The immediate use of gender information: Eyetracking evidence of the time-course of pronoun resolution. Cognition, 76, B13-B26.

Arnold, J. E., \& Lao, S-Y. C. (2007). Put in last position something previously unmentioned: Word order effects on referential expectancy and reference comprehension. Language and Cognitive Processes, 23, 282-295.

Boersma, P. (2001). PRAAT, a system for doing phonetics by computer. Glot International, 5, 341-345. 
Dowty, D. (1991). Thematic roles and argument selection. Language, 67, 547-619.

Fillmore, C. (1968). The case for case. In E. Bach \& R. Harms (Eds.), Universals of linguistic theory (pp. 1-90). New York: Holt, Rhinehart and Winston.

Foraker, S., \& McElree, B. (2007). The role of prominence in pronoun resolution: Active versus passive representations. Journal of Memory and Language, 56, 357-383.

Gernsbacher, M. A., \& Hargreaves, D. (1988). Accessing sentence participants: The advantage of first mention. Journal of Memory and Language, 27, 699-717.

Givon, T. (Ed.). (1983). Topic continuity in discourse: A quantitative cross-language study. Amsterdam: John Benjamins.

Gordon, P. C., Grosz, B. J., \& Gilliom, L. A. (1993). Pronouns, names and the centering of attention in discourse. Cognitive Science, 17, 311-347.

Gundel, J., Hedberg, N., \& Zacharski, R. (1993). Cognitive status and the form of referring expressions in discourse. Language, 69, 274-307.

Hopper, P. J., \& Thompson, S. A. (1980). Transitivity in grammar and discourse. Language, 56, 251-299.

Huettig, F., \& Altmann, G. T. M. (2005). Word meaning and the control of eye fixation: Semantic competitor effects and the visual world paradigm. Cognition, 96, B23-B32.

Howell, D. C. (2002). Statistical methods for psychology. (5th ed.). Pacific Grove, CA: Duxbury.

Jackendoff, R. (1972). Semantic interpretation in generative grammar. Cambridge, MA: MIT Press.

Järvikivi, J., Van Gompel, R. P. G., Hyönä, J., \& Bertram, R. (2005). Ambiguous pronoun resolution: Contrasting the first-mention and subject-preference accounts. Psychological Science, 16, 260-264.

Kako, E. (2006). Thematic role properties of subjects and objects. Cognition, 101, 1-42.

Koornneef, A. W., \& Van Berkum, J. J. A. (2006). On the use of verb-based implicit causality in sentence comprehension: Evidence from self-paced reading and eye tracking. Journal of Memory and Language, 54, 445-465.

Knoeferle, P., \& Crocker, M. W. (2006). The coordinated interplay of scene, utterance, and world knowledge: Evidence from eye tracking. Cognitive Science, 30, 481-529.

Knoeferle, P., \& Crocker, M. W. (2007). The influence of recent scene events on spoken comprehension: evidence from eye-movements. Journal of Memory and Language, 57, 519-543.

Knoeferle, P., Crocker, M. W., Scheepers, C., \& Pickering, M. J. (2005). The influence of the immediate visual context on incremental thematic role-assignment: evidence from eye-movements in depicted events. Cognition, 95, 95-127.

MacWhinney, B. (2000). The CHILDES project: Tools for analyzing talk (Vol. 2: The database). London: Lawrence Erlbaum Associates.

Matin, E., Shao, K. C., \& Boff, K. R. (1993). Information-processing time with and without saccades. Perception and Psychophysics, 53, 372-380.

McKoon, G., Greene, S. B., \& Ratcliff, R. (1993). Discourse models, pronoun resolution, and the implicit causality of verbs. Journal of Experimental Psychology: Learning, Memory and Cognition, 19, 1040-1052.

Pyykkönen, P., \& Järvikivi, J. (in press). Activation and persistence of implicit causality information during spoken language comprehension. Experimental Psychology.

Rose, R. L. (2005). The relative contribution of syntactic and semantic prominence to the salience of discourse entities. Unpublished $\mathrm{PhD}$, Northwestern University.

Scheepers, C. (2003). Syntactic priming of relative clause attachment: Persistence of structural configuration in sentence production. Cognition, 89, 179-205.

Song, H., \& Fisher, C. (2006). Who's "she"? Discourse structure influences preschoolers' pronoun interpretation. Journal of Memory and Language, 52, $29-57$.

Song, H., \& Fisher, C. (2007). Discourse prominence effects on 2.5-year-old children's interpretation of pronouns. Lingua, 117, 1959-1987.

Speas, M. (1990). Phrase structure in natural language. Dordrecht: Kluwer Academic Publishers. 
Stevenson, R. J., Knott, A., Oberlander, J., \& McDonald, S. (2000). Interpreting pronouns and connectives: Interactions among focusing, thematic roles and coherence relations. Language and Cognitive Processes, 15, 225-262.

Stevenson, R. J., Crawley, R. A., \& Kleinman, D. (1994). Thematic roles, focus and the representation of events. Language and Cognitive Processes, 9, 519-548.

Tanenhaus, M. K., Spivey-Knowlton, M. J., Eberhard, K. M., \& Sedivy, J. C. (1995). Integration of visual and linguistic Information in spoken language comprehension. Science, 268, 1632-1634.

Theakston, A. L., Lieven, E. V. M., Pine, J. M., \& Rowland, C. F. (2001). The role of performance limitations in the acquisition of verb-argument structure: An alternative account. Journal of Child Language, 28, 127-152.

Weber, A., Grice, M., \& Crocker, M. W. (2006). The role of prosody in the interpretation of structural ambiguities: A study of anticipatory eye movements. Cognition, 99, B63-B72.

\section{Appendix A \\ Rating questions for the verb 'Chase'}

Given the sentence: 'Jane chased Kate'

How likely is it that Jane chose to be involved in chasing?

How likely is it that Jane was aware of being involved in chasing?

How likely is it that Jane caused a change in Kate?

How likely is it that Jane caused Kate to do something?

How likely is it that Jane moved?

How likely is it that Jane existed before chasing took place?

How likely is it that Kate was changed in some way as a result of chasing?

How likely is it that Kate was created as a result of chasing?

How likely is it that Kate was stationary? 